\title{
A formação continuada do Pacto Nacional pelo Fortalecimento do Ensino Médio na Gerência Regional de Educação de Chapecó, SC
}

\section{The continous training of National Covenant for Improving High School in Regional Education Management of Chapecó, SC}

\section{La formación continuada del Pacto Nacional pelo Fortalecimiento de la Enseñanza Media en la Gerencia Regional de Educación de Chapecó, SC}

Sandra Maria Zardo Morescho'

Universidade Comunitária da Região de Chapecó (Unochapecó), atua no Grupo de Pesquisa Ensino e Formação de Professores

Nadir Castilho Delizoicou ${ }^{2}$

Universidade Comunitária da Região de Chapecó (Unochapecó), Professora do Programa de Pós-graduação em Educação

Resumo: Este artigo apresenta dados de pesquisa qualitativa sobre a formação continuada de professores ofertada por meio do Pacto Nacional pelo Fortalecimento do Ensino Médio (PNEM) nos anos 2014 e 2015. O objetivo no trabalho foi investigar as percepções dos orientadores de estudo do Pacto sobre a formação desenvolvida com professores de 10 escolas públicas estaduais pertencentes à Gerência Regional de Educação (Gered) de Chapecó, no Oeste de Santa Catarina. Os dados foram obtidos por meio de entrevista semiestruturada, e a análise apresenta o parecer do orientador de estudo, as dificuldades enfrentadas e o término do PNEM diante da Reforma do Ensino Médio. Os resultados indicaram a significância da formação, que contribuiu para o reconhecimento do estudante do ensino médio enquanto sujeito. A finalização do PNEM é tida como aspecto lamentável, associada ao temor do

Mestre em Educação pela Universidade Comunitária da Região de Chapecó (Unochapecó); Doutoranda no Programa de Pós-graduação em Educação da Universidade de Passo Fundo (PPGEDU/UPF).

2 Doutora e Mestre em Educação pela Universidade Federal de Santa Catarina. 
aumento da desvalorização e precarização da docência com a Reforma do Ensino Médio.

Palavras-chave: PNEM. Orientador de estudo. Formação continuada de professores. Reforma do Ensino Médio.

Abstract: This paper presents data from a qualitative research on a continuous training of teachers, carried out through the National Covenant for Improving High School (PNEM) in 2014 and 2015. This research aimed to investigate the perceptions of the study supervisors of the covenant on the training developed with teachers from ten state public schools belonging to the Regional Education Management (Gered) of Chapecó, in the West of Santa Catarina. The data were obtained through a semi-structured interview and the analysis presents the opinion of the study supervisors, difficulties faced during the training process and the evaluation about the end of the PNEM in the face of the High School Reform. The results indicated the significance of the training, especially for contributing to the recognition of the high school student as a subject. The end of PNEM is considered a regrettable aspect, associated with the fear of increasing devaluation and precariousness of teaching with the High School Reform.

Keywords: PNEM. Study supervisors. Continuous teacher training. High School Reform.

Resumen: Este artículo presenta datos de pesquisa cualitativa sobre la formación continuada de profesores, ofrecida por medio del Pacto Nacional pelo Fortalecimiento de la Enseñanza Media (PNEM) en los años de 2014 y 2015. El objetivo del trabajo fue investigar las percepciones de los orientadores de estudio del Pacto sobre la formación desarrollada junto a profesores de diez escuelas públicas estaduales pertenecientes a la Gerencia Regional de Educación (Gered) de Chapecó, en el Oeste de Santa Catarina. Los datos fueron obtenidos a través de entrevista semiestructurada y el análisis presenta el parecer de orientadores de estudio, dificultades enfrentadas durante el proceso formativo y la evaluación acerca del término del PNEM delante de la Reforma de la Enseñanza Media. Los resultados indicaron la importancia de la formación, especialmente por contribuir para el reconocimiento del estudiante de la enseñanza secundaria como sujeto. La finalización del PNEM es considerada como aspecto lamentable, relacionada al temor del aumento 
de la desvalorización y precarización de la docencia con la Reforma de la Enseñanza Media.

Palabras clave: PNEM. Orientador de estudio. Formación continuada de profesores. Reforma de la Enseñanza Media.

\section{INTRODUÇÃO}

O Pacto Nacional pelo Fortalecimento do Ensino Médio (PNEM) constituiu-se em um processo de formação continuada de professores realizado nos anos 2014 e 2015 . Neste trabalho, apresentamos os resultados de uma pesquisa que investigou as percepções do orientador de estudo, figura importante durante a realização do Pacto, sobre o processo de formação continuada do PNEM na Gerência Regional de Educação (Gered) de Chapecó, SC. ${ }^{3}$ No texto discute-se sobre a importância da formação inicial para a docência. Apresenta-se, também, a formação continuada e seus conceitos, bem como a necessidade de que seja ofertada ao longo da atividade docente. Em seguida, apresenta-se a formação realizada pelo PNEM, seus objetivos e o papel do orientador de estudo no processo de mediação junto aos professores pertencentes à Gered de Chapecó, SC. Na sequência, apresentamos o parecer do orientador de estudo sobre o PNEM, as dificuldades enfrentadas durante a formação, bem como do término do Programa com a implantação da Reforma do Ensino Médio.

\section{A DOCÊNCIA E A FORMAÇÃO CONTINUADA: A NECESSIDADE DE UM ELO PERMANENTE}

A atividade docente requer uma ampla diversidade de conhecimentos para a condução dos processos de ensino e de aprendizagem. A constituição

\footnotetext{
3 Os dados fazem parte de Dissertação de Mestrado defendida junto ao Programa de Pós-graduação stricto sensu em Educação da Universidade Comunitária da Região de Chapecó (Unochapecó).
} 
desses conhecimentos tem seu início na formação inicial, primordial para o exercício da docência. No entanto, a formação docente não se conclui com o término da formação inicial, tornando-se necessária sua continuidade ao longo da vida profissional, por meio de processos intencionais e planejados que induzam a mudanças nas práticas em sala de aula (ANDRÉ, 2010). Uma formação constante ao longo da profissão docente se torna necessária ao professor para o processo de mediação entre os conhecimentos socialmente construídos e o estudante (MIZUKAMI, 1996). Nesse sentido, a formação docente, de modo permanente, é fundamental para o direcionamento do trabalho com os discentes e para a concretização dos processos de ensino e de aprendizagem.

Segundo Alvaro-Prada, Freitas e Freitas (2010), a formação do sujeito ocorre durante toda a vida, em que o ser humano, inserido em um meio com outros indivíduos, relaciona-se, interage, aprende com eles e incorpora esse aprendizado. Processo semelhante ocorre com a formação docente, que se constitui em uma "[...] contínua caminhada dos profissionais da educação, em cujo caminhar atuam todas as suas dimensões individuais e coletivas de caráter histórico, biopsicossocial, político, cultural, próprias de seres integrais e autores de sua própria formação." (ALVARO-PRADA; FREITAS; FREITAS, 2010, p. 370).

Diante do exposto, Alvaro-Prada, Freitas e Freitas (2010) destacam, ainda, que a escola é o principal espaço para a formação continuada dos professores, pois essa formação também deriva da realidade vivenciada. A instituição escolar é compreendida não apenas como o espaço de atuação dos professores, mas de vivência com outros profissionais e estudantes, considerando que a vida escolar está inserida em um cotidiano para além da escola. "A construção da formação docente envolve toda a trajetória dos profissionais, suas concepções de vida, de sociedade, de escola, de educação, seus interesses, necessidades, habilidades e também seus medos, dificuldades e limitações." (ALVARO-PRADA; FREITAS; FREITAS, 2010, p. 370).

Para Candau (1996), a escola precisa ser reconhecida como lócus de formação, possibilitando que, por meio de uma prática reflexiva, o professor consiga identificar os problemas existentes nesse espaço e, no coletivo, planeje soluções para a superação dessas dificuldades. Silva e Araújo (2005) destacam 
quatro conceitos sobre a reflexão na ação, compreendida como toda atividade docente. Esses conceitos integram "[...] o conhecimento na ação; a reflexão na ação; a reflexão sobre a ação; e a reflexão para a ação. Aqui se entende por ação toda a atividade profissional do professor." (SILVA; ARAÚJO, 2005, p. 2). Para os autores, o conhecimento na ação demonstra que os saberes do professor se constituem por meio da sua experiência e das atividades intelectuais, permitindo que sejam utilizados diariamente na atividade docente para o alcance de objetivos preestabelecidos.

Tratando-se da formação continuada de professores no Brasil, observa-se uma trajetória marcada por concepções diversas, constituídas a partir de diferentes percepções de educação e sociedade presentes na realidade brasileira. É importante destacar que "[...] foi especificamente na década de 1990 que a formação continuada passou a ser considerada uma das estratégias fundamentais para o processo de construção de um novo perfil profissional do professor." (ARAÚJO; ARAÚJO; SILVA, 2015, p. 59).

Para Santos (1998), a formação continuada permite a qualificação profissional docente, por meio do domínio de conhecimentos e métodos que podem contribuir para a superação de problemas na prática docente. Nesse percurso, é possível acrescentar novos conhecimentos que se relacionem aos saberes em diferentes áreas, contribuindo para a atualização do professor.

Nascimento (201 1 ) remete à formação continuada todas as atividades que contribuam para a qualificação do trabalho pedagógico ofertadas após a formação inicial do professor. Entre elas estão incluídas as atividades formativas oferecidas pelos sistemas de ensino, como cursos de especialização e extensão realizados pelas instituições de ensino superior.

Já para Gatti e Barreto (2009, p. 203), a formação continuada constituise em um movimento orientado ao longo da profissão docente, associado ao desenvolvimento profissional do professor, a fim de chegar às respostas para os desafios encontrados nas diferentes fases da docência: "[...] o início da carreira, o processo de desenvolvimento e os tempos mais avançados em que o professor consolida a sua experiência profissional." Os novos conhecimentos de que o professor se apropria lhe permitem reformular seus saberes. No entanto, 
é fundamental que haja um estímulo, uma motivação para que a formação tenha continuidade, ao mesmo tempo que os conhecimentos para a docência se transformam e passam a contribuir para mudanças na prática pedagógica, que ocorrem com mais facilidade quando o professor está motivado e inspirado a fazer diferente.

Diante da importância da formação docente, o professor precisa estar disposto a se desafiar constantemente para novos aprendizados, buscar e construir novos saberes, envolvendo o educando no fazer pedagógico, de modo que realizem trocas e cresçam juntos nesse processo. $\bigcirc$ reconhecimento da condição de inacabamento do ser humano estimula a necessidade de uma formação constante, sendo que, para Freire (1996), é a consciência desse inacabamento em que homens e mulheres se reconhecem em um processo de construção permanente, uma vez que todos os seres vivos são inacabados. No entanto, apenas os homens e as mulheres, na condição consciente desse inacabamento, educam-se, ação que constitui o propósito da educação.

A autorreflexão permite que o sujeito se reconheça na sua condição de inacabamento, ao refletir sobre si mesmo, identificando-se com um ser na busca constante pelo empoderamento. Como educador, a consciência de inacabamento provoca-o a aproximar-se "[...] da natureza do ser que é capaz de se comprometer" (FREIRE, 1979, p. 16), aproximando-o da significância do ato comprometido. Assim, ao se comprometer com uma formação constante, o professor demonstra sua ligação com a educação, o que só é possível por meio de sua ação e reflexão.

A importância da formação permanente é defendida por Freire (1999) em favor do desenvolvimento de um trabalho sério, rigoroso e competente. Os resultados permitem a reflexão sobre a prática pedagógica, principal finalidade da formação permanente, bem como a reflexão para novas possibilidades para o desenvolvimento dessa prática (FREIRE, 1999).

A formação permanentemente induz $\circ$ professor a refletir constantemente sobre seus saberes e sobre as experiências que se fazem presentes na prática docente com o estudante. Conforme Freire (1979, p. 20), "quanto mais me capacito como profissional, quanto mais sistematizo minhas 
experiências, quanto mais me utilizo do patrimônio cultural, que é patrimônio de todos e ao qual todos devem servir, mais aumenta minha responsabilidade com os homens."

\section{PNEM: A FORMAÇÃO MEDIADA PELO ORIENTADOR DE ESTUDO}

O PNEM foi instituído por meio da Portaria n. 1.140, de 22 de novembro de 2013, em parceria entre o Ministério da Educação (MEC) e as Secretarias Estaduais e Distrital de Educação. O compromisso do PNEM direcionou-se à valorização da formação continuada dos professores e coordenadores do ensino médio de escolas públicas, tendo como meta rediscutir e atualizar as práticas docentes em conformidade com as Diretrizes Curriculares Nacionais do Ensino Médio (DCNEM) (BRASIL, 2013a).

A formação ofertada pelo PNEM foi desenvolvida nos anos 2014 e 2015, na modalidade presencial, nas escolas de atuação dos professores de ensino médio que participaram do processo, tendo como tema: Sujeitos do Ensino Médio e Formação Humana Integral. A ação foi direcionada a melhorar a qualidade do ensino médio, ampliando os espaços de formação dos profissionais envolvidos nessa etapa da educação básica, permitindo a reflexão sobre as atividades curriculares desenvolvidas nas escolas e promovendo o desenvolvimento de práticas educativas que evidenciassem a formação humana integral (BRASIL, 2016a).

De acordo com Zardo Morescho (2017), durante sua realização, o PNEM teve como base a leitura, a reflexão e a discussão dos temas presentes nos cadernos de estudo, os quais foram produzidos na Universidade Federal do Paraná (UFPR) e utilizados na formação dos professores, induzindo à articulação entre as diferentes áreas do conhecimento a partir da realidade vivenciada na escola. A primeira etapa, realizada em 2014, foi composta por uma formação comum a todos os participantes, em que foram estudados os cadernos ensino médio e formação humana integral; o jovem como sujeito do ensino médio; o currículo do ensino médio, seus sujeitos e o desafio da 
formação humana integral; áreas de conhecimento e integração curricular; organização e gestão democrática da escola; avaliação no ensino médio. Em 2015, período correspondente à segunda etapa, os cadernos direcionaram-se para a organização do trabalho pedagógico no ensino médio e para as áreas do conhecimento: Linguagens, Ciências Humanas, Ciências da Natureza e Matemática. A organização atendeu à proposta das DCNEM, que demandam que os docentes compreendam os componentes curriculares em sua totalidade e possam desenvolver novas formas de organização do conhecimento escolar, com a ampliação das possibilidades de integração entre as diferentes áreas do conhecimento (BRASIL, 2014). Tendo como proposta a formação integral do sujeito, o PNEM evidenciou a importância de olhar para o estudante do ensino médio, reconhecendo-o como um indivíduo que possui conhecimentos e interesses, para, assim, relacioná-los aos conteúdos trabalhados.

Durante a vigência do Programa, a formação ofertada aos professores foi mediada pelos orientadores de estudo, profissionais escolhidos por meio de processo seletivo público, em suas respectivas escolas, atendendo aos requisitos da Portaria n. 1.140/2013 (BRASIL, 2013a). Dentre os critérios estabelecidos pela Portaria, para atuar na função na unidade escolar, o profissional da educação deveria atuar como docente em sala de aula ou ser coordenador pedagógico no ensino médio em escola da rede estadual, estar em efetivo exercício em 2014 e constar no Censo Escolar de 2013 da respectiva rede a que estivesse vinculado. $\bigcirc$ orientador de estudo deveria, ainda, permanecer como professor ou coordenador pedagógico no quadro efetivo do magistério da rede pública de sua rede de ensino durante toda a realização do Pacto.

\section{APRESENTAÇÃO E ANÁLISE DOS DADOS}

Para a realização da pesquisa da qual resulta o presente artigo, obteve-se, na Gered de Chapecó, SC, a relação das escolas que ofertam o ensino médio e que estavam, à época, envolvidas com o PNEM. Das 28 escolas, foram selecionadas 10 , aquelas que tinham o maior número de professores 
cursistas, com o objetivo de localizar os orientadores de estudo sujeitos da pesquisa. Dessa forma, obteve-se um total de 12 orientadores, pois em duas escolas a formação foi mediada por dois deles, em razão de o número de professores ser considerado alto, aproximadamente 40 sujeitos. Os dados foram coletados por meio de entrevista semiestruturada aplicada individualmente.

Os profissionais selecionados, e que contribuíram para a realização deste estudo, pertencem a escolas de ensino médio da Gered de Chapecó, que fazem parte da Rede Estadual de Ensino de Santa Catarina. São efetivos e trabalham 40 horas-aulas semanais em funções que variam entre assistente técnico pedagógico, orientador educacional, assistente de educação e professor. $\bigcirc$ tempo de serviço varia entre 10 e 32 anos, sendo que todos possuem licenciatura plena, seguida de especialização e dois entrevistados possuem mestrado, um em Educação e outro em História. Os dados coletados por meio da entrevista semiestruturada foram analisados tendo como base a análise de conteúdo (BARDIN, 1979). Foram eleitas três categorias de análise (LUNA, 1997): parecer do orientador de estudo sobre o PNEM, dificuldades enfrentadas durante a formação e o término do PNEM diante da implantação da Reforma do Ensino Médio, as quais são discutidas na sequência deste texto.

\subsection{PARECER DO ORIENTADOR DE ESTUDO SOBRE A FORMAÇÃO DO PNEM}

Após a realização das duas etapas de formação do PNEM, nos anos 2014 e 2015, os orientadores de estudo ouvidos na pesquisa consideraram que o PNEM contribuiu para mudanças significativas nas escolas em que foi mediado, tendo reconhecida sua importância para a formação do professor do ensino médio.

A formação foi descrita positivamente, destacando a relevância dos temas trabalhados nos cadernos do Pacto, direcionados ao estudante desse nível de ensino, tratando-se de seu reconhecimento enquanto sujeito, em uma perspectiva de formação humana integral: "Na escola a gente fez uma 
avaliação ao final da formação, e o coletivo de professores avaliou que foi uma das melhores formações que eles já fizeram." (OE5, informação verbal). ${ }^{4}$

Os orientadores destacaram a importância dos encontros nos quais a formação era realizada, pois, além de proporcionar a interação entre os docentes, esses momentos permitiam a reflexão das práticas pedagógicas e a discussão dos problemas existentes na escola. Dessa forma, tornou-se possível pensar na superação das dificuldades, bem como na troca de experiências e conhecimentos entre os profissionais, fatores que contribuíram para que o PNEM fosse avaliado como uma formação de qualidade:

O PNEM foi importantíssimo no sentido de permitir discutir os reais problemas que tínhamos dentro da escola. Enquanto a gente estudava os textos dos cadernos, [...] percebíamos uma clara relação daqueles problemas, aquelas situações e sugestões de trabalho para nossa realidade escolar. Nas reuniões do PNEM tivemos a oportunidade de discutir isso. Dificilmente temos outros momentos para reunir os professores do ensino médio para essas discussões e, eram nesses momentos, que surgiam as ideias e conseguíamos produzir projetos novos para a escola. (OE9, informação verbal).

A partir das falas dos orientadores de estudo, observa-se a significância do PNEM para a formação do professor e, consequentemente, para o estudante do ensino médio, que esteve no centro das discussões. No entanto, é importante destacar que a formação destinada aos professores do ensino médio não é um fato comum. Esse aspecto foi consenso entre os entrevistados, que reconhecem que as formações nas escolas geralmente são direcionadas aos professores do ensino fundamental: "Foi um programa bom, pensando na formação para o ensino médio, que geralmente não se tem muita prioridade [...] as formações são direcionadas mais para o ensino fundamental." (OE2); "Não tinha mais capacitação a esse nível há muito tempo, principalmente para o ensino médio." (OE7, informações verbais).

\footnotetext{
4 A fim de garantir o anonimato dos sujeitos da pesquisa, nos trechos transcritos eles serão identificados pela sigla $\mathrm{OE}$ (Orientador de Estudo) seguida do número correspondente à ordem das entrevistas.
} 
Um dos propósitos do PNEM foi incentivar a aproximação entre o professor e o aluno, principalmente por meio do diálogo (ZARDO MORESCHO, 2017). Mas não foi apenas uma aproximação entre docentes e discentes que - PNEM proporcionou. A formação induziu a uma maior aproximação entre os professores, o que possibilitou um trabalho coletivo, direcionado inclusive para planejar estratégias a serem desenvolvidas na prática, por meio da interdisciplinaridade. Adaptar o currículo, considerando a proximidade dos conteúdos das diferentes disciplinas, possibilita ao estudante relacionar os temas trabalhados em várias situações e assimilar os conceitos com mais facilidade, materializando-se a aprendizagem em um trabalho interdisciplinar: "A maioria conseguiu captar esse novo olhar, adaptar de maneira diferente suas metodologias [...] através da interdisciplinaridade." (OE8). A interdisciplinaridade, por sua vez, foi associada à formação humana integral do jovem do ensino médio: "[...] foi através do PNEM que se começou a pensar os primeiros passos da formação humana integral, da escola integral, do trabalho por áreas do conhecimento, que até este momento percebo como ponto positivo em nossa escola." (OE12, informações verbais).

Ao verificar a literatura presente nos cadernos da formação do PNEM, observa-se que uma das propostas pressupunha a formação humana integral, agregando aspectos científicos, humanísticos e culturais à aprendizagem "[...] a formação humana integral implica competência técnica e compromisso ético, que se revelem em uma atuação profissional pautada pelas transformações sociais, políticas e culturais necessárias à edificação de uma sociedade igualitária." (BRASIL, 2013c, p. 34). A formação humana integral preconiza formar o sujeito em sua totalidade, contemplando as dimensões "[...] intelectual, afetiva, social, corpórea, com vistas a propiciar um itinerário formativo que potencialize o desenvolvimento humano em sua plenitude, que se realiza pelo desenvolvimento da autonomia intelectual e moral" (BRASIL, 2013d, p. 32), contribuindo para a existência de um indivíduo autônomo para a vida em sociedade.

Durante a realização do PNEM, os orientadores de estudo observaram em suas escolas mudanças significativas na avaliação do estudante do ensino médio. $O$ caderno de estudo do PNEM relacionado à avaliação (BRASIL, 2013b) recomendava que esta fosse realizada durante o desenvolvimento 
do programa curricular, de modo paralelo, em que o professor pudesse fazer sua autoavaliação enquanto mediador da aprendizagem, revisando suas estratégias e repensando seu planejamento. Essas ações permitiram ao estudante do ensino médio se reconhecer como sujeito no processo de aprendizagem, de modo que ele conseguisse visualizar seus progressos, identificando em quais aspectos ainda poderia melhorar. É desejável que este seja o papel da avaliação: um instrumento para o sucesso na aprendizagem dos estudantes, considerando, inclusive, sua individualidade. É ideal que o processo avaliativo seja reconhecido pelo estudante como um instrumento a serviço de sua aprendizagem e não como uma punição, constituindo-se como ponto de apoio para interferências futuras, considerando fragilidades, limites e potencialidades de cada sujeito, contando com a intervenção do professor (BRASIL, 2013b).

Para os orientadores de estudo, o PNEM contribuiu para o reconhecimento da condição de sujeito do estudante do ensino médio. É desejável que cada sujeito seja visto em sua individualidade, como alguém que vivencia uma determinada realidade além da escola. $\bigcirc$ professor que participou da formação teve a chance de desenvolver esse olhar diferenciado para com o estudante do ensino médio: "[...] com o PNEM houve muitas mudanças, até como os professores veem os alunos do ensino médio." (OE7); "[...] o aluno passou a ser visto com outro olhar, o professor começou a desenvolver outras atividades, ouvir o aluno de forma diferente." (OE6, informações verbais).

Entre as falas dos orientadores de estudo, observa-se um fator que se estende além do reconhecimento da importância do PNEM, que é o interesse do professor em participar dos processos de formação continuada. Na maioria das escolas dos orientadores que colaboraram para a pesquisa, a formação foi realizada além do horário de trabalho do professor. A proposta do PNEM era que a formação fosse realizada no horário de trabalho, nos momentos de planejamento. No entanto, em muitos casos não havia a possibilidade de conciliar os horários dos professores, já que vários deles cumpriam a jornada de trabalho em diferentes escolas. "O PNEM trazia isso: que era para nós organizarmos dentro da hora-atividade do professor. É claro, a Gerência de Educação dizia isso. Mas também dizia que nós tínhamos que tentar organizar 
da forma que a escola conseguisse. Porque cada escola é diferente." (OE5, informação verbal).

Os orientadores de estudo mencionaram que, mesmo exigindo um tempo a mais de dedicação, esse não foi um motivo para que os docentes não realizassem ou desistissem do PNEM. Desse modo, evidencia-se o desejo do professor em continuar seu percurso formativo ao longo da carreira; vislumbrase a preocupação em adquirir novos conhecimentos, com momentos de encontro para estudo e formação, de interação com os pares para reflexão de sua prática pedagógica, troca de experiências, impulsionados pela vontade de melhorar cada vez mais seu trabalho, como já destacado por Zardo Morescho (2017). O professor se reconhece na condição de inacabamento, que o direciona à formação permanente, visto que esse é um processo que ocorre e se estende ao longo de sua vida, na interação, relação e aprendizado com outros sujeitos, fato que acontece inclusive entre os profissionais da educação (ALVARO-PRADA; FREITAS; FREITAS, 2010).

\subsection{DIFICULDADES ENFRENTADAS DURANTE A FORMAÇÃO}

Dentre as dificuldades mencionadas pelos orientadores de estudo estão os casos de professores que não realizaram ou não finalizaram a formação do PNEM em virtude de dificuldades relacionadas à vida pessoal e à incompatibilidade com os horários estabelecidos para realização da formação. No entanto, os orientadores de estudo destacaram principalmente aquelas enfrentadas pelos professores Admitidos em Caráter Temporário (ACTs). As dificuldades desses profissionais compreendem desde o não recebimento da bolsa de estudo até a falta de informações em tempo hábil, que esclareceriam para a realização da formação (ZARDO MORESCHO, 2017).

não recebimento da bolsa de estudo foi um problema enfrentado por professores de todo o País durante a realização do PNEM. $\bigcirc$ motivo se deve por não constarem na relação do Censo Escolar do ano 2013. A Portaria n. 1.140/2013 (BRASIL, 2013a), que instituiu o PNEM, em seu artigo 19, inciso II, 
determinava que um dos critérios para que os professores que participassem do PNEM recebessem a bolsa de estudo seria constar no Censo Escolar de 2013, na respectiva rede a que estivessem vinculados. No entanto, muitos dos professores que realizaram a formação na Gered de Chapecó, na época, não eram efetivos na rede.

Em razão da rotatividade, ano após ano, o professor ACT corre o risco de mudar de escola e/ou mesmo de rede de ensino. Dependendo de seu desempenho e/ou classificação nos processos seletivos para o ingresso no magistério para a educação básica, o professor ACT pode ser admitido em caráter temporário na rede municipal, bem como na rede estadual, ou, ainda, buscar uma vaga na rede particular. No entanto, o fato de ter um vínculo empregatício, mesmo que temporário, não significa que seja sempre no início do ano letivo. $O$ professor ACT é contratado conforme a necessidade da rede de ensino, em qualquer período do ano letivo e seu contrato será rescindido assim que seu trabalho não tenha mais necessidade. Diante do exposto, no momento da realização do Censo Escolar de 2013, é evidente que inúmeros professores ACTs estavam na rede estadual, e outros docentes, certamente, contratados em outras redes de ensino.

Analisando os critérios estabelecidos na Portaria n. 1.140/2013 e avaliando que o professor que não constasse no Censo Escolar de 2013 não teria o direito à formação e à bolsa de estudo, torna-se visível uma séria incoerência, principalmente com os professores que estivessem vinculados ao ensino médio, pois nesse nível de ensino, conforme Thiesen (2016, p. 15),

[...] é a etapa com maior percentual de professores contratados em caráter temporário e a que concentra mais expressiva média em termos de aulas ministradas por semana e atuação em maior número de escolas por professor. Somente estes dados são suficientes para demonstrar as precárias condições de trabalho a que está submetido este coletivo.

Para os orientadores de estudo, a exclusão da formação dos docentes que não constavam na relação do Censo Escolar do ano 2013 foi considerada 
uma falha lamentável, diante da importância da formação para o professor do ensino médio, questão que estava além dos limites dos mediadores da formação:

Agora, não posso deixar de relatar que tem alguns professores que não fizeram porque não ganhavam bolsa, porque eles não estavam na época do Censo Escolar. Então, isto também foi um equívoco, uma questão de sede. Quem estava afastado da escola não foi contado no censo e não recebeu bolsa. Tiveram pessoas que não fizeram o PNEM porque não ganharam bolsa. (OEl0, informação verbal).

Diante do comentário, pode-se comprovar que a bolsa de estudo mobilizou a participação dos docentes, e, para o professor que não correspondia aos critérios da referida Portaria, o não pagamento da bolsa de estudo se tornou um fator de desmotivação e desmobilização para participar da formação.

Outro fator mencionado pelos orientadores de estudo que dificultou o pagamento da bolsa de estudo e, consequentemente, ocasionou a falta de participação de alguns docentes no Programa foi a inscrição do professor não ter sido realizada em tempo hábil: "Existiram vários professores que não realizaram a formação [...] devido a questões particulares, por não terem sido inscritos em tempo no Programa. Aí, como eles não estavam recebendo bolsa, eles não quiseram participar." (OEl l, informação verbal).

Segundo Durli (2016), os resultados de uma pesquisa que trata da avaliação do PNEM em Santa Catarina, direcionada às percepções dos orientadores de estudo e dos formadores regionais, apontam que uma comunicação mais efetiva, com mais clareza sobre todo o processo, seria um fator que poderia ter sido mais eficaz. A afirmação é feita considerandose que houve problemas de comunicação em relação à organização e encaminhamento da formação, originados ainda no Ministério da Educação: "As informações imprecisas, a demora entre a pré-inscrição e a matrícula propriamente dita, os problemas e a falta de informações sobre o sistema, bem como a demora na implementação das bolsas geraram muito desencontro." (DURLI, 2016, p. 243). Os problemas de comunicação, além de interferirem na formação dos orientadores de estudo e formadores regionais, prejudicaram 
também a formação de inúmeros professores do ensino médio. Nesse sentido, Durli (2016) identificou em sua pesquisa a necessidade de que as informações sejam prestadas com mais organização e clareza, considerando que o fator foi um empecilho, principalmente para os professores ACTs, o que se confirma na fala do OE4 (informação verbal):

[...] ficou bem complicado. Na primeira etapa eles [os professores] estavam bem tranquilos, participavam, conseguíamos organizar com eles também. Sempre marcávamos no horário em que eles poderiam participar. Mas na segunda etapa ficou aquela confusão, na verdade falta de informações: vai poder participar, não vai poder, pode na escola em que está trabalhando, continua no sistema onde estava, quem não fez a primeira etapa poderia iniciar [...] ficaram muitas dúvidas.

Segundo Zardo Morescho (2017), não estar vinculado à rede estadual de ensino no momento da realização do Censo Escolar de 2013 contribuiu para que muitos docentes não recebessem a bolsa de estudo, mesmo que, durante o PNEM, estivessem trabalhando com o ensino médio. $\mathrm{Na}$ segunda etapa da realização da formação, no ano 2015, as informações desencontradas continuaram sem a objetividade desejada, comprometendo novamente a participação do professor ACT. Existiram casos de professores que não realizaram a primeira etapa da formação, mas constavam na relação do Censo Escolar de 2014. Estes tinham interesse em participar da segunda etapa do PNEM, porém necessitavam de informações sobre as possibilidades de realizar ou não a formação do ano 2015. Diante do exposto, inúmeros professores ACTs deram continuidade à formação, enquanto outros ficaram aguardando as orientações, fator que comprometeu a frequência, anulando o direito à bolsa de estudo e ao certificado.

Por outro lado, mesmo tendo realizado a primeira etapa da formação no ano 2014, existiram professores ACTs que não conseguiram dar continuidade à segunda etapa do PNEM por não terem sido contratados no ano 2015, visto que um dos critérios para a participação era estar trabalhando com o aluno do ensino médio, vinculado à rede estadual de ensino. "Teve uma ruptura em dezembro e janeiro para iniciar a segunda etapa. Muitos professores ACTs 
mudaram de escola e [...] na segunda etapa não continuaram. Foram para outras instituições, em lugares que não havia o PNEM ou saíram da rede estadual." (OE8, informação verbal).

Alguns não conseguiram acompanhar 100\%. Teve um professor que fez a primeira etapa e não concluiu a segunda porque não pegou mais aula no ano seguinte, terminou seu contrato [...] ele não foi contratado novamente em 2015. Não sendo contratado, ele não poderia prosseguir o curso. Então esse professor só recebeu as 100 horas da primeira etapa. Ele não concluiu em escola nenhuma, pois até então, no início da formação, ele não tinha contrato e não tendo contrato, não poderia continuar o curso. Essa era a orientação que a gente recebia do formador. (OE 12 , informação verbal).

Segundo informações obtidas com os orientadores de estudo na segunda etapa da formação, realizada no ano 2015, o professor que estivesse atuando com o ensino médio e que tivesse realizado a primeira etapa do PNEM poderia continuar a segunda etapa na mesma escola em que havia trabalhado no ano 2014, mesmo que estivesse lecionando em outra unidade escolar. No entanto, poderia também continuar a formação na escola em que estivesse contratado no ano 2015. "Entre os ACTs que não retornaram para a nossa escola no ano de 2015, alguns concluíram a formação conosco, porque ficaram próximos da nossa escola." (OE5, informação verbal). A ação possibilitou que o professor ACT continuasse o PNEM na escola em que iniciou a formação, tendo em vista que o professor efetivo dificilmente troca de escola. Diante do exposto, havia a necessidade de clareza para essa informação, bem como de considerar que os debates do PNEM na segunda etapa seriam realizados conforme a realidade da escola em que os docentes estivessem fazendo a formação:

Não culpo o professor, porque ele não é o culpado. Não fechavam mais os horários. Alguns professores queriam fazer com a gente. Alguns continuaram em outras escolas, sendo certificados. Só não terminaram no nosso grupo. Teve professores que mudaram de cidade e fizeram em outra cidade. Só não terminaram conosco. A minha parte e a deles ficou fragmentada, não pegando todo o processo. Não avalio como um problema do professor, 
de falta de vontade ou de desinteresse. A maior parte foi de problemas de mudança de escola, de endereço, os horários não fechavam mais e não tinha mais como eles fazerem conosco. (OE5, informação verbal).

A perda do direito à bolsa de estudo para os casos de professores ACTs que não constassem no Censo foi uma limitação. No entanto, a partir do relato dos orientadores de estudo, observou-se que existiram casos de professores ACTs que, mesmo sem a bolsa de estudo, realizaram a formação: "Tive professores que participaram de toda a formação mesmo sem receber a bolsa. Inclusive eles eram dois do grupo dos mais empenhados, dos mais envolvidos na formação. Percebe-se que eles efetivamente vestiram a camisa da educação [...]" (OE9, informação verbal).

Em várias das escolas nas quais os orientadores de estudo ouvidos para a pesquisa que resultou neste artigo atuaram, nos grupos de formação, havia a presença de docentes que não eram bolsistas e foi registrado, também, o empenho do professor em retornar à escola em que iniciou o PNEM para concluir o processo. Mesmo sem receber a bolsa de estudo, a atitude dos professores em realizar a formação demonstra seu compromisso com a docência, participando de um processo formativo diante da vontade de aperfeiçoar cada vez mais o seu trabalho e se tornar cada vez melhor na mediação dos processos de ensino e de aprendizagem. Formar-se constantemente demonstra o interesse do professor em ser um intelectual transformador, como propõe Giroux (1997), a fim de refletir sobre sua prática para torná-la cada vez melhor, assegurando uma educação de qualidade ao estudante.

Diante do exposto, observa-se que dar continuidade ao percurso formativo durante a carreira demonstra o reconhecimento do professor de sua condição de inacabamento. Homens e mulheres estão em construção permanente durante sua vida (FREIRE, 1996). Refletir sobre si permite que os sujeitos se reconheçam na condição de construção permanente, em que se faz necessária a busca constante de novos conhecimentos para sua construção e, consequentemente, para sua formação profissional (FREIRE, 1979). Comprometer-se com a formação constante é se comprometer com a educação, 
sendo reconhecida sua importância quando o professor não apenas necessita, mas quer ter o direito à formação continuada ao longo de sua carreira.

\subsection{A FINALIZAÇÃO DO PNEM COM A IMPLANTAÇÃO DA REFORMA DO ENSINO MÉDIO}

Após a finalização da primeira e da segunda etapa do PNEM, realizadas nos anos 2014 e 2015, os orientadores de estudo aguardavam por uma suposta terceira etapa. Entretanto, o PNEM foi interrompido, fato que foi lamentado pelos orientadores de estudo: "Quando o Programa acabou, a segunda etapa não teve sequência, deu aquela parada na escola e acabou se perdendo um pouco essa empolgação, a empolgação que os professores tinham." (OE2); "Nós esperávamos que continuasse, pois as mudanças mais significativas iriam acontecer com a continuidade do PNEM. Houve mudanças, mas existem muitas coisas para mudar ainda." (OE5, informações verbais).

A formação do PNEM motivava os professores para o trabalho, demonstrando a necessidade da formação continuada na escola e, como consequência, a ocorrência de mudanças nesse espaço. $\bigcirc$ PNEM proporcionava aos professores do ensino médio momentos de discussão, reflexão, planejamento e problematização das dificuldades da escola, ações que confirmam a proposta de formação continuada de Candau (1996), de considerar a escola como lócus de formação, lugar em que o professor realiza seu trabalho e com ele ocorrem suas experiências e aprendizados no seu dia a dia, uma vez que "Nesse cotidiano ele aprende, desaprende, reestrutura o aprendido, faz descobertas e, portanto, é nesse locus que muitas vezes ele vai aprimorando a sua formação." (CANDAU, 1996, p. 144).

Com o fim do PNEM os professores não dispõem mais desse tempo para o diálogo, um diálogo específico que impulsionava a troca de informações, planejamento, articulação de um trabalho coletivo, bem como a discussão das dificuldades e das angústias que envolviam a escola: 
[...] a escola precisa de momentos para sentar, para discutir, com orientação de textos, sugestões de atividades, com trocas de ideias. Precisamos ter constantemente essa formação continuada que o PNEM proporcionou. Não de apenas ouvir o estudioso falando, não apenas ler aquilo que o estudioso escreve, mas no sentido de poder trocar as ideias, de poder discutir, de poder sugerir, pensar estratégias coletivamente. Considero que a perda está nesse sentido. (OE9, informação verbal).

Se, no período de sua realização, o PNEM motivava os docentes para mudanças em suas práticas, com o fim da formação, não há mais um tempo destinado ao coletivo, em que os professores anteriormente dialogavam e articulavam um trabalho conjunto. "[...] era um momento que proporcionava o diálogo entre os professores que conseguiam trocar informações sobre o que trabalhavam e o que poderiam trabalhar juntos. Só que eu observo que foi um momento. Um momento dos 10 meses do Pacto." (OEl, informação verbal). Percebe-se, assim, que o término do PNEM, além de interromper a formação dos professores do ensino médio, interrompeu todo um trabalho que a formação continuada impulsionava.

Segundo Moll (2017), durante sua realização, o PNEM previa um número significativo de ações, como:

[...] a recuperação na infraestrutura das escolas, o avanço no acesso aos meios tecnológicos, o estímulo ao desenvolvimento do pensamento científico e do aprendizado de línguas estrangeiras, as bolsas para professores de ensino médio em processo de formação [...] (MOLL, 2017, p. 68).

O Pacto implicaria, ainda, o diálogo entre as redes públicas e as escolas, considerando "[...] que há sim, muita vida inteligente na educação básica, materializada em experiências exitosas de configurações pedagógicas e curriculares no ensino médio." (MOLL, 2017, p. 68).

Durante a realização desta pesquisa, os orientadores de estudo entrevistados manifestaram a necessidade da continuidade da formação, de forma permanente, a fim de que os professores pudessem refletir sobre sua 
prática e sobre os problemas enfrentados no cotidiano escolar. No entanto, no mesmo período, após o impeachment da Presidenta Dilma Roussef, as mudanças políticas para o ensino médio se evidenciavam, gerando certo pessimismo em relação à continuidade do PNEM e de investimentos na formação continuada dos professores do ensino médio. "[...] com todas essas mudanças que estão ocorrendo hoje, eu não acredito que o PNEM continue, principalmente com os cortes financeiros que estão tendo na educação." (OE5, informação verbal).

Para Moll (2017), as mudanças que estavam ocorrendo no ensino médio direcionavam para uma maior eficácia na participação dos professores e equipe pedagógica das escolas. Sem esse movimento, corre-se o risco de induzir a mudanças homogeneizadoras, não correspondendo à realidade cultural, social e produtiva local, que podem ser modificadas e qualificadas em tempo se os jovens forem inseridos de forma respeitosa e diferenciada da qual se vive atualmente. Tratando-se da formação docente, a autora demonstra a significância desse processo nos avanços educacionais, já que "[...] nenhuma mudança na educação escolar pode ser levada a sério sem um efetivo projeto de formação inicial e continuada de professores e equipes gestoras das escolas." (MOLL, 2017, p. 72).

Após sua interrupção no ano 2015, a certeza do fim do PNEM ocorreu em 2016, com a Medida Provisória n. 746, de 22 de setembro de 2016, que, em 16 de fevereiro de 2017, passa a vigorar na Lei n. 13.415/2017, que instituiu a Reforma do Ensino Médio (BRASIL, 2017). Para Silva e Sheibe (2017), trata-se de uma Reforma imposta por Medida Provisória arbitrária, sem o diálogo com a sociedade, cujas mudanças afetarão diretamente milhares de jovens brasileiros, levando à fragmentação do currículo escolar e à negação do direito à formação básica comum, o que pode contribuir ainda mais para reforçar as desigualdades educacionais. Uma medida impositiva e arbitrária, demonstrando que a cada mudança de governo se modificam as políticas educacionais, sem considerar as políticas anteriores, sempre com o propósito de inovação, com a justificativa de melhorar a qualidade na educação.

Em relação à Reforma do Ensino Médio, Moura e Lima Filho (2017) destacam que os discursos oficiais do Governo e de seus apoiadores difundiam a crítica de suposta "ineficiência e falta de flexibilidade" nesse 
nível de ensino da rede pública, nas redes estaduais e federal de educação profissional e tecnológica, mantendo um discurso para uma reforma urgente, não possibilitando um debate social e democrático.

Os principais argumentos que justificaram a Reforma de forma rápida e arbitrária se vincularam à ideologia neoliberal, criticando principalmente o "currículo rígido", que fazia necessária sua substituição por um "currículo enxuto e dinâmico", como itinerários formativos diferenciados, a fim de valorizar a escolha dos estudantes de acordo com seus interesses, favorecendo, assim, o protagonismo juvenil, em uma escola de tempo integral (MOURA; LIMA FILHO, 2017). Um fato preocupante é que a cada reforma educacional e/ou implementação de políticas públicas educacionais, tem se tornado um episódio corriqueiro desconsiderar as pesquisas e os conhecimentos produzidos no campo educacional. Na maioria das vezes, o professor fica limitado a executar, na prática, as leis aprovadas por sujeitos que, via de regra, desconhecem a realidade do ensino e das escolas públicas brasileiras, citando como exemplo a Lei n. 13.415/2017, que instituiu a Reforma do Ensino Médio (BRASIL, 2017). Os docentes tiveram negada a oportunidade de contribuir com seus conhecimentos para a implementação dessa nova política, ação que os tem reduzido ao papel de consumidores de novas políticas de governo, juntamente com seus educandos.

Além de modificar a Lei de Diretrizes e Bases da Educação Nacional, Lei n. 9.394/1996, que compreende que a educação envolve os processos formativos na vida familiar, na convivência humana, no trabalho, nas instituições de ensino e pesquisa, nos movimentos sociais e organizações da sociedade civil e nas manifestações culturais (BRASIL, 1996), a Reforma do Ensino Médio (BRASIL, 2017) desconsidera as práticas, os conhecimentos e experiências dos docentes e discentes da educação básica. Tratando-se das experiências positivas vivenciadas nas escolas até então, Moura e Lima Filho (2017) denunciam que estas são omitidas no discurso oficial dos governantes, especialmente em se tratando daquelas relacionadas ao Ensino Médio Integrado à educação profissional (EMI), o qual é realizado em inúmeras escolas estaduais e federais da rede pública. Escolas que se destacaram na qualidade do ensino ofertado, com as condições de funcionamento necessárias "[...] aliadas à concepção de 
formação humana integral, com a integração entre ciência, tecnologia, cultura e trabalho, com eixos norteadores do currículo" (MOURA; LIMA FILHO, 2017, p. 120), conforme constava na proposta de formação do PNEM. Nessas escolas, os autores, ainda, destacam que os resultados de avaliações como o Exame Nacional do Ensino Médio (ENEM) e o Programa Internacional de Avaliação de Alunos (Pisa) demonstram que as médias alcançadas pelos estudantes foram superiores às demais redes "[...] e, em alguns casos, às de alunos de países da Organização para a Cooperação e Desenvolvimento Econômico (OCDE)." (MOURA; LIMA FILHO, 2017, p. 120). O caso mencionado pelos autores evidencia que bons resultados podem ser alcançados pelos estudantes das escolas públicas, fato que foi omitido pelas autoridades que tanto apressaram e defenderam a proposta de reforma do ensino médio.

A qualidade do ensino público é um debate constante e apreensivo envolvendo professores e sistemas de ensino, a fim de que o estudante possa ter a possibilidade de melhorar suas condições de vida por meio da educação e, ao finalizar o ensino médio, tenha oportunidades para ingressar na universidade, almejando uma profissão. Dentre essas propostas, o PNEM contou com um grande investimento financeiro para sua realização, uma vez que todos os envolvidos na formação, abrangendo desde Coordenador Geral do Pacto da IES até o professor que atua no ensino médio, recebiam bolsa de estudo ${ }^{5} \mathrm{com}$ valores diferenciados de acordo com as funções. Com o congelamento dos gastos para a educação por meio da Emenda Constitucional n. 95 (BRASIL, 2016b), cresceu uma desesperança quanto a uma educação de qualidade. Considerando que formar professores para elevar a qualidade da educação no ensino médio foi um dos objetivos do PNEM, hoje, com os investimentos limitados existe a preocupação de que a educação fique comprometida em sua totalidade, levando em conta a infraestrutura, materiais didáticos, bolsas de estudo, remuneração dos professores e recursos para serem investidos nos processos de formação continuada.

\footnotetext{
5 Mais informações sobre as funções do PNEM, bem como sobre o valor das bolsas destinadas podem ser encontradas no documento orientador das ações de formação continuada de professores e coordenadores pedagógicos do Ensino Médio em 2014, o qual pode ser encontrado por meio do link a seguir: <http://pactoensinomedio.mec.gov.br/images/pdf/documento_orientador.pdf>
} 
É importante destacar ainda que a Lei n. 13.415/2017, que institui a Política de Fomento à Implementação de Escolas de Ensino Médio em Tempo Integral, amplia a carga horária de 800 horas anuais para 1.400 horas progressivamente (BRASIL, 2017). Para sua implementação, a Política de Fomento prevê repasse de recursos do MEC para os estados e para o Distrito Federal por um período de 10 anos por escola, a partir da data de implementação do ensino médio em tempo integral. Amaral (2017), ao realizar uma análise sobre a Lei n. 13.415/2017, considera que não há uma definição de valores a serem transferidos, uma vez que o valor por aluno matriculado que consta no Censo Escolar da Educação Básica dependerá da disponibilidade de orçamento para atendimento, que será definido pelo MEC. Com a ampliação da jornada escolar em tempo integral para 1.400 horas anuais, sem assegurar investimentos constantes, questiona-se a qualidade do ensino ofertado, aumentando a possibilidade de aumento da evasão entre os jovens que frequentam o ensino médio.

Outra questão preocupante que se configura com a Reforma do Ensino Médio é a diluição de disciplinas estruturantes que possibilitam uma rica fundamentação teórica construída ao longo da história. Castilho (2017) defende que a premissa da escolha do itinerário formativo no sistema público é inverídica, uma vez que a escola e/ou rede de ensino proporcionará o currículo de acordo com suas condições de oferta, evidenciando que a informação divulgada por meio da mídia de que o estudante poderá escolher seu itinerário formativo não é verdadeira. A Lei n. 13.415/2017 orienta que a organização das áreas, de suas competências e habilidades seja de acordo com critérios estabelecidos em cada sistema de ensino, que poderá compor o itinerário formativo integrado de acordo com a Base Nacional Comum Curricular (BNCC) e itinerários formativos das áreas do conhecimento e/ou formação técnica e profissional (BRASIL, 2017). No entanto, se a oferta do itinerário formativo depende das condições que a escola e/ou a rede pública de ensino possui, o estudante terá que cursar o que a escola ou sistema ofertar, e, sendo as redes de ensino que estabelecerão as ênfases ou itinerários a serem cursados, reforçamse as desigualdades de oportunidades educacionais. Moll (2017) considera que existe a necessidade de mudanças na estrutura do ensino médio brasileiro. 
No entanto, defende que o problema não será resolvido com a retirada de componentes curriculares que contribuem para o desenvolvimento da visão de mundo dos estudantes. Para a autora:

Novos desenhos curriculares, alicerçados em projetos de investigação e de inserção, acompanhados por professores de diferentes áreas, em diálogo, podem nos levar a outro patamar de oferta da educação básica, bem como a qualificação da infraestrutura e da carreira docente. (MOLL, 2017, p. 72).

Cabe destacar, ainda, que um dos aspectos observados na Lei n. 13.415/2017 corresponde à desvalorização da formação do professor, pois a Lei abre a possibilidade de qualquer profissional não licenciado exercer o magistério, por meio do reconhecimento do "notório saber". Moura e Lima Filho (2017, p. 125) afirmam que a Lei n. 13.415/2017 pode contribuir para a "[...] desvalorização, a desqualificação e o ataque à formação e profissionalidade dos docentes [...]" que compõem a educação básica, em especial o ensino médio. Conforme a Lei da Reforma do Ensino Médio, são considerados profissionais da educação básica os profissionais com notório saber, reconhecidos pelo sistema de ensino em que atuam para ministrar conhecimentos segundo sua formação e experiência profissional, bem como de sua formação técnica e profissional.

Carrano (2016) e Castilho (2017) argumentam que a ação contribui para a desvalorização da formação de professores, precariza a docência, comprometendo a qualidade do ensino ofertado. Estando de acordo com os autores mencionados, Moura e Lima Filho (2017) alertam para o risco de precarização geral das condições de trabalho, seja dos docentes licenciados, seja daqueles com notório saber. Para estes, a docência, em grande parte dos casos, apresenta-se como uma atividade de renda complementar, na qual o acúmulo de vínculos intensifica o trabalho, com contratos temporários simultâneos e vulneráveis, tendo como consequência o comprometimento da qualidade dos processos de ensino e de aprendizagem.

Abrir mão de uma formação específica, considerando o notório saber e a experiência profissional, induz à desvalorização profissional do magistério. 
A ação se constitui em uma afronta ao docente que percorreu a formação inicial, prosseguindo com a formação continuada ao longo de sua carreira. $\bigcirc$ profissional habilitado e licenciado submete-se a um processo de concorrência com aquele que, ao comprovar seu notório saber em qualquer habilitação técnica, recebe o certificado para exercer a docência (SILVA, 2017).

É lastimável que as autoridades políticas não considerem a importância da formação do professor, tornando nítido o descaso com a formação docente para uma educação de qualidade, visto que "A formação do professor é indispensável porque há saberes e competências que são específicos da docência. Ensinar bem uma matéria não requer apenas saber o conteúdo - é preciso compreender o complexo processo ensino-aprendizagem." (CASTILHO, 2017).

Por trás de uma proposta atraente e inovadora, a Reforma do Ensino Médio fere princípios de igualdade entre os estudantes, em relação às condições de acesso e permanência na escola, bem como o êxito nas avaliações para ingresso no ensino superior. Para os profissionais da educação, desvaloriza-os diante do reconhecimento do notório saber, fazendo pouco caso da formação docente, que deveria ser constante ao longo da carreira do professor, tornando cada vez mais distante o desejo de uma formação continuada, ofertada de forma permanente, como a que vinha sendo desenvolvida pelo PNEM.

\section{CONSIDERAÇÕES FINAIS}

O PNEM foi um programa de formação continuada ofertado em nível nacional, assumido pelo MEC e pelas secretarias estaduais e distrital de educação. Teve como objetivo valorizar a formação continuada dos profissionais da educação envolvidos com o ensino médio, ao mesmo tempo que direcionava à discussão e atualização das práticas docentes de acordo com as DCNEM (BRASIL, 2013a).

Diante da análise do parecer dos orientadores de estudo que mediaram a formação aos docentes pertencentes à Gered de Chapecó, situada 
no Oeste do Estado de Santa Catarina, considera-se que a formação ofertada proporcionou momentos de estudo, reflexão e discussão, possibilitando que os temas estudados pudessem ser relacionados com a realidade vivenciada nas escolas e com a prática docente, ao mesmo tempo que os professores trocavam conhecimentos e experiências entre si, contribuindo para o trabalho coletivo. $\bigcirc$ PNEM teve sua significância e qualidade reconhecidas, com temas relevantes direcionados ao percurso formativo do jovem do ensino médio na perspectiva de uma formação humana integral.

Os orientadores de estudo ouvidos afirmaram que o PNEM proporcionou mudanças significativas na prática pedagógica dos docentes, destacando principalmente o trabalho interdisciplinar que começou a ser desenvolvido entre os professores das diferentes áreas do conhecimento; mudanças positivas na forma de avaliar o estudante, considerando sua formação integral e o reconhecimento do estudante enquanto sujeito, na sua individualidade e na vida além daquela vivenciada dentro dos muros da escola.

Mesmo com as dificuldades enfrentadas durante a formação, em relação à falta de informações em tempo hábil para sua realização e às limitações enfrentadas pelos professores ACTs, pontuadas também por Durli (2016) e Thiesen (2016), estas não impediram que muitos docentes fizessem a formação, mesmo sem a bolsa de estudo. A atitude demonstra que o professor tem interesse pela formação continuada, quer seguir com o percurso formativo ao longo de sua carreira, tem a vontade de ser um intelectual transformador, o que demonstra seu comprometimento com um ensino de qualidade.

Infelizmente, as mudanças no cenário político brasileiro levaram à finalização do PNEM e instituíram a Reforma do Ensino Médio, por meio da Lei n. 13.415/2017, demonstrando que as políticas educacionais representam os interesses de governo, com a promessa de superação de todos os problemas por meio da oferta de uma educação de qualidade.

A partir da análise do aporte teórico que subsidiou esta breve fundamentação sobre a Reforma do Ensino Médio, bem como da Lei n. 13.415/2017, observa-se que a política induz a educação a sérios riscos, como a desvalorização da formação do professor e a precarização da docência, 
oferecendo um currículo fragmentado ao estudante, composto por itinerários formativos, sem a garantia de escolha conforme a área de interesse do estudante, bem como de investimentos para a consolidação e qualidade da educação ofertada.

Mesmo com as mudanças significativas que vinham sendo observadas em nível de ensino médio e na formação do estudante, estas foram desconsideradas e omitidas pelas lideranças políticas, com argumentos que impunham a qualquer preço uma reforma no ensino médio, em tempo integral, com condições desiguais, acentuando ainda mais as diferenças educacionais.

Diante dos relatos dos orientadores, a importância do PNEM para a formação do professor do ensino médio foi reconhecida, confirmando que a formação inicial necessita ter continuidade ao longo da carreira docente, por meio de uma formação permanente, que contribua para o empoderamento do professor diante de seu inacabamento. Com a realização do PNEM, foi possível observar que, quando há vontade política e investimentos, é possível ofertar formação docente sistematicamente organizada, de qualidade, com temas direcionados à formação integral do jovem que cursa o ensino médio, considerando-o para além da escola. Uma formação que proporcione estudos, reflexões, valorização do professor, bem como de seus conhecimentos e suas experiências a partir de seu cotidiano escolar. Infelizmente, a finalização do PNEM encerra uma ação que contribuiu significativamente para um processo de formação continuada do professor do ensino médio. Restam agora as novas mudanças para essa etapa da educação básica, que colocam em risco a valorização da formação do professor, comprometendo os princípios do direito à igualdade e uma educação de qualidade para todos os estudantes.

\section{REFERÊNCIAS}

ALVARO-PRADA, L. E.; FREITAS, T. C. de; FREITAS, C. A. Formação continuada de professores: alguns conceitos, interesses, necessidades e propostas. Revista Diálogo, Curitiba, v. 10, n. 30, p. 367-387, maio/ago. 2010. Disponível em: <http://www2.pucpr.br/reol/pb/index.php/dialogo?ddl =36l4\&dd9 $9=$ view\&dd98=pb> . Acesso em: 02 jan. 2016. 
AMARAL, N. C. $\bigcirc$ "novo" ensino médio e o PNE: haverá recursos para essa política? Retratos da Escola. Escola de Formação da Confederação Nacional dos Trabalhadores em Educação - Esforce, Brasília, DF: CNTE, v. 1 l, n. 20, p. 91-108, jan./jun. 2017.

ANDRÉ, M. Formação de professores: a constituição de um campo de estudos. Educação, Porto Alegre, v. 33, n. 3, p. 174-181, set./dez. 2010. Disponível em: <http://revistaseletronicas.pucrs.br/ojs/index.php/faced/article/ view/8075/5719>. Acesso em: 25 jan. 2016.

ARAÚJO, C. M. de; ARAÚJO, E. M.; SILVA, R. D. da. Para pensar sobre a formação continuada de professores é imprescindível uma teoria crítica de formação humana. Cadernos Cedes, Campinas, v. 35, n. 95, p. 57-73, jan./abr. 2015. Disponível em: <http://www.scielo.br/pdf/ccedes/v35n95/0101-3262-ccedes-35-95-00057.pdf>. Acesso em: 08 jan. 2016.

BARDIN, L. Análise de Conteúdo. Lisboa: Edições 70, 1979.

BRASIL. Ministério da Educação. Lei de Diretrizes e Bases da Educação Nacional. 1996. Disponível em: <http://portal.mec.gov.br/arquivos/pdf/ldb. pdf>. Acesso em: 08 jan. 2016.

BRASIL. Ministério da Educação. Pacto Nacional pelo Fortalecimento do Ensino Médio. 2016a. Disponível em: <http://pactoensinomedio.mec.gov.br/ index. php?option $=$ com_content\&view $=$ article\&id $=22>$. Acesso em: 09 jun. 2016.

BRASIL. Ministério da Educação. Portaria n. 1.140. Diário Oficial da União, Brasília, DF, 05 dez. 2013a. Disponível em: <http://portal.mec.gov.br/index. php?option =com_docman\&view =download\&alias = 15069-pacto-dou- 1 -2\&category_slug=janeiro-2014-pdf\&Itemid=30192>. Acesso em: 09 jun. 2016.

BRASIL. Ministério da Educação. Secretaria de Educação Básica. Formação de Professores do Ensino Médio: avaliação no ensino médio. Etapa I, Caderno VI. Curitiba: Ed. UFPR, 2013b.

BRASIL. Ministério da Educação. Secretaria de Educação Básica. Formação de Professores do Ensino Médio: ensino médio e formação humana integral. Etapa I, Caderno I. Curitiba: Ed. UFPR, $2013 c$.

BRASIL. Ministério da Educação. Secretaria de Educação Básica. Formação de Professores do Ensino Médio: o currículo do Ensino Médio, seus sujeitos e o desafio da formação humana integral. Etapa I, Caderno III. Curitiba: Ed. UFPR, 2013d. 
BRASIL. Ministério da Educação. Secretaria de Educação Básica. Formação de Professores do Ensino Médio: organização do trabalho pedagógico no ensino médio. Etapa II, Caderno I. Curitiba: Ed. UFPR, 2014.

BRASIL. Palácio do Planalto. Lei n. 13.415, de 16 de fevereiro de 2017. Portal da Legislação, 2017. Disponível em: < http://www.planalto.gov.br/ccivil_03/_ ato2015-2018/2017/lei/113415.htm>. Acesso em: 09 abr. 2017.

BRASIL. Presidência da República. Casa Civil. Subchefia para assuntos Jurídicos. Emenda Constitucional n. 95, de 15 de dezembro de 2016. 2016b. Disponível em: <http://www.planalto.gov.br/ccivil_03/constituicao/emendas/ emc/emc95.htm>. Acesso em: 17 jul. 2018.

CANDAU, V. M. F. Formação continuada de professores: tendências atuais. In: REALI, A. M. de M. R.; MIZUKAMI, M. da G. N. (Org.). Formação de professores: tendências atuais. São Carlos: EdUFSCar, 1996. p. 139-152.

CARRANO, P. Nota pública da ANPEd sobre a Medida Provisória do Ensino Médio. MP do Ensino Médio - Autoritária na forma e equivocada em conteúdo. Anped, 23 set. 2016. Disponível em: < http://www.anped.org.br/news/ nota-publica-da-anped-sobre-medida-provisoria-do-ensino-medio>. Acesso em: 24 jan. 2017.

CASTILHO, D. Reforma do Ensino Médio: desmonte na educação e inércia do enfrentamento retórico. Pragmatismo político. Educação, 21 fev. 2017. Disponível em: <http://www.pragmatismopolitico.com.br/2017/02/reforma-do-ensino-medio-desmonte-educacao-inercia.html>. Acesso em: 11 mar. 2017.

DURLI, Z. et al. A avaliação da formação no âmbito do PNEM em Santa Catarina: desafios e possibilidades de um processo. In: ANDREIS, A. M.; SIMÕ̃S, W. (Org.). O PNEM em Santa Catarina: reflexões sobre as vivências na formação continuada de professores. Tubarão: Copiart, 2016. p. 227-259.

FREIRE, P. A educação na cidade. 3. ed. São Paulo: Cortez, 1999.

FREIRE, P. Educação e Mudança. Rio de Janeiro: Paz e Terra, 1979.

FREIRE, P. Pedagogia da Autonomia: saberes necessários à prática educativa. São Paulo: Paz e Terra, 1996.

GATTI, B. A.; BARRETO, E. S. de S. Professores do Brasil: impasses e desafios. Brasília, DF: Unesco, 2009. 
GIROUX, H. A. Professores como intelectuais transformadores. Os professores como intelectuais: rumo a uma pedagogia crítica da aprendizagem. Porto Alegre: Artmed, 1997.

LUNA, S. V. de. Planejamento de Pesquisa: uma introdução. São Paulo: EDUC, 1997.

MIZUKAMI, M. da G. N. Docência, trajetórias pessoais e desenvolvimento profissional. In: REALI, A. M. de M. R.; MIZUKAMI, M. da G. N. (Org.). Formação de professores: tendências atuais. São Carlos: EdUFSCAR, 1996. p. 59-89.

MOLL, J. Reformar para retardar: a lógica da mudança no EM. Retratos da Escola. Escola de Formação da Confederação Nacional dos Trabalhadores em Educação - Esforce, Brasília, DF: CNTE, v. 1 l, n. 20, p. 61-74, jan./jun. 2017.

MOURA, D. H; LIMA FILHO, D. L. A reforma do ensino médio: regressão de direitos sociais. Retratos da Escola. Escola de Formação da Confederação Nacional dos Trabalhadores em Educação - Esforce, Brasília, DF: CNTE, v. 11, n. 20, p. 109-129, jan./jun. 2017.

NASCIMENTO, M. G. Formação continuada de professores: modelos, dimensões e problemática. In: CANDAU, V. M. (Org.). Magistério: construção cotidiana. 7. ed. Petrópolis: Vozes, 201 l. p. 69-90.

SANTOS, L. L. de C. P. Dimensões pedagógicas e políticas da formação contínua. In: VEIGA, I. P. A. (Org.). Caminhos da profissionalização do magistério. Campinas: Papirus, 1998. p. 123-136.

SILVA, M. R. da. Como fica o ensino médio com a reforma - vem aí o ensino médio "líquido". CEDES, 17 fev. 2017. Disponível em: <http://www.cedes. unicamp.br/noticias/668>. Acesso em: 11 mar. 2017.

SILVA, M. R. da; SHEIBE, L. Reforma do ensino médio: pragmatismo e lógica mercantil. Retratos da Escola. Escola de Formação da Confederação Nacional dos Trabalhadores em Educação - Esforce, Brasília, DF: CNTE, v. 11, n. 20, p. 19-31, jan./jun. 2017.

SILVA, E. M. A.; ARAÚJO, C. M. de A. Reflexão em Paulo Freire: uma contribuição para a formação continuada de professores. In: COLÓQUIO INTERNACIONAL PAULO FREIRE, 5., 2005, Recife. Anais... Recife, 2005. Disponível em: <http://189.28.128.100/nutricao/docs/Enpacs/pesquisaArtigos/reflexao_em_paulo_freire_2005.pdf>. Acesso em: 03 jan. 2016. 
THIESEN, J. da S. A formação de professores no contexto do Pacto Nacional pelo Fortalecimento do Ensino Médio em Santa Catarina: desafios e êxitos de uma primeira experiência. In: ANDREIS, A. M.; SIMÕES, W. (Org.). O PNEM em Santa Catarina: reflexões sobre as vivências na formação continuada de professores. Tubarão: Copiart, 2016. p. 5-26.

ZARDO MORESCHO, S. M. Formação continuada de professores: a percepção do orientador de estudo sobre o PNEM na GERED de Chapecó - SC. 2017. Dissertação (Mestrado em Educação)-Universidade Comunitária da Região de Chapecó, Chapecó, 2017.

Recebido em 30 de janeiro de 2018 Aceito em 23 de julho de 2018

Endereços para correspondência: Rua Maria Ranzan, 464 E, Bairro Rosa Linda, 89819-000, Cordilheira Alta, Santa Catarina, Brasil; samaza@unochapeco.edu.br 